\title{
Philadelphia Telemedicine Glaucoma Detection and Follow-Up Study: Cataract Classifications Following Eye Screening
}

Lisa A. Hark, PhD, $R D_{,}^{1,2}$ Jennifer Adeghate, $M D_{1}^{3}$

L. Jay Katz, MD, ${ }^{1,4}$ Mikdat Ulas, $B S^{4}$ Michael Waisbourd, $M D^{5}$ Alisha Maity, BA, ${ }^{4}$ Tingting Zhan, PhD, ${ }^{6}$ Sarah Hegarty, MPhil, ${ }^{6}$ Benjamin E. Leiby, $P h D_{1}{ }^{6}$ Louis R. Pasquale, MD, ${ }^{7}$ Stela Leite, $M D{ }^{1}$ Jinan B. Saaddine, $M D^{8}$ Julia A. Haller, $M D_{1}^{4,9}$ and Jonathan S. Myers, $M D^{1,4}$

${ }^{1}$ Wills Eye Hospital, Glaucoma Research Center, Philadelphia, Pennsylvania, USA.

${ }^{2}$ Columbia University Vagelos College of Physicians and Surgeons, Edward S. Harkness Eye Institute, New York, New York, USA.

${ }^{3}$ University of Pittsburgh, Department of Ophthalmology, Pittsburgh, Pennsylvania, USA.

${ }^{4}$ Sidney Kimmel Medical College, Thomas Jefferson University, Philadelphia, Pennsylvania, USA.

${ }^{5}$ Division of Ophthalmology, Tel-Aviv Medical Center, Tel-Aviv University Sackler Faculty of Medicine, Tel-Aviv, Israel.

${ }^{6}$ Division of Biostatistics, Department of Pharmacology and Experimental Therapeutics, Sidney Kimmel Medical College, Philadelphia, Pennsylvania, USA.

${ }^{7}$ Icahn School of Medicine at Mount Sinai, Department of Ophthalmology, New York, New York, USA.

${ }^{8}$ Centers for Disease Control and Prevention, Division of Diabetes and Translational Research, Vision Health Initiative, Atlanta, Georgia, USA.

${ }^{9}$ Wills Eye Hospital, Ophthalmologist-in-Chief, Philadelphia, Pennsylvania, USA.

\section{Abstract}

Background: Cataracts are a major cause of visual impairment and blindness in the United States and worldwide.

Introduction: Risk factors for cataracts include age over 40 years, smoking, diabetes, low socioeconomic status, female sex, steroid use, ocular trauma, genetic factors, and exposure to ultraviolet-B light. Community-based telemedicine vision screenings can be an efficient method for detecting cataracts in underserved populations. The Philadelphia Telemedicine Glaucoma Detection and Follow-Up Study reports the prevalence and risk factors for cataracts in individuals screened and examined for glaucoma and other eye diseases.

Materials and Methods: A total of 906 high-risk individuals were screened for glaucoma using telemedicine in seven primary care practices and four Federally Qualified Health
Centers in Philadelphia. Participants with suspicious nerves or other abnormalities on fundus photographs, unreadable images, and ocular hypertension returned for an eye examination with an ophthalmologist at the same community location.

Results: Of the participants screened through telemedicine, 347 (38.3\%) completed a follow-up eye examination by an ophthalmologist. Of these, 267 (76.9\%) were diagnosed with cataracts, of which 38 (14.2\%) had visually significant cataracts. Participants who were diagnosed with visually significant cataract were more likely to be older ( $<<0.001)$, have diabetes $(\mathrm{p}=0.003)$, and worse visual acuity $(\mathrm{p}<0.001)$.

Discussion: Our study successfully detected and confirmed cataracts in a targeted, underserved urban population at high risk for eye disease.

Conclusions: Telemedicine programs offer an opportunity to identify and refer individuals who would benefit from continuous follow-up eye care and treatment to improve visual function and quality of life.

Keywords: telemedicine, m-health, telecommunications, ophthalmology, cataract

\section{Introduction}

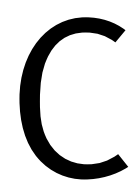

ataracts are a major cause of visual impairment and blindness in the United States and worldwide, representing a significant public health problem. ${ }^{1-4}$ In 2010, cataracts impacted nearly 25 million people nationwide and over 110 million individuals worldwide. ${ }^{1-4}$ Due to the rapidly aging population of the United States, the prevalence of cataracts is projected to double by 2050, affecting over 50 million people. ${ }^{2}$ Risk factors for developing cataracts include age $>40$ years, smoking, diabetes, low socioeconomic status, female, steroid use, ocular trauma, genetic factors, and exposure to ultraviolet-B light. ${ }^{5,6}$ There are also differences in cataract type, incidence, prevalence, and disease progression between races, with Caucasians having the highest prevalence (18.8\%), followed by African Americans (13\%) and Hispanics (11.8\%). ${ }^{2}$

Cataract surgery is the most common surgery performed in all of medicine and has been shown to improve vision and 


\section{CATARACT CLASSIFICATIONS FOLLOWING EYE SCREENING}

positively impact quality of life. ${ }^{7,8}$ However, due to socioeconomic and racial disparities in the prevalence of cataracts and cataract surgery, accessibility of the procedure throughout the United States is variable. ${ }^{9,10}$ Socioeconomic status and psychosocial factors, such as lack of access to eye care, limited knowledge of cataract surgery, lack of medical insurance to cover surgery, lack of trust in surgical outcomes, and language barriers, contribute to these disparities. ${ }^{1-13}$ It has been shown that improving communication and rapport between surgical centers and underserved communities increases cataract surgery rates. ${ }^{14}$

Community-based vision screening programs may also detect cataracts in underserved populations and offer follow-up eye care and cataract surgery. ${ }^{15,16}$ Telemedicine is a promising screening technique that has been utilized in ophthalmology and has been shown to reduce eye care barriers by providing affordable accessible eye examinations. ${ }^{17,18}$ Images obtained through telemedicine are made available to ophthalmologists, and in conjunction with clinical information, allow for evaluation of ocular pathology and disease progression. ${ }^{19}$ As technology improves, the use of smartphones for detection of ocular disease may increase and further reduce the costs of eye screenings. ${ }^{20,21}$

The Philadelphia Telemedicine Glaucoma Detection and Follow-Up Study is a 5-year, randomized controlled trial designed to assess the effectiveness of a primary care practice (PCP)-based telemedicine screening model for detecting glaucoma and other eye diseases in high-risk populations. ${ }^{22}$ This article presents a cross-sectional prevalence analysis of participants who screened abnormal and were diagnosed with cataracts following a comprehensive eye examination by an ophthalmologist in the primary care setting.

\section{Materials and Methods}

The study was approved by the Wills Eye Hospital's Institutional Review Board/Ethics Committee (No. 14-441) and was conducted in accordance with the Declaration of Helsinki. Written and verbal informed consent was obtained from all participants. The clinical trial is registered with ClinicalTrials.gov (NCT 02390245). The detailed methods of this study have been published previously. ${ }^{22}$

The study targeted high-risk populations from multiple geographically and ethnically diverse communities throughout Philadelphia, and participants were recruited with the help of community partners. Eligible individuals were predominantly African American, Hispanic, or Asian over age 40 years; adults over age 65 years; and adults of any ethnicity over age 40 years with a family history of glaucoma and/or diabetes. Individuals seen by an eye care provider (ophthalmologist or optometrist) within the past year and those cur- rently followed by an eye care provider (ophthalmologist or optometrist) with previously diagnosed glaucoma, glaucoma suspect, or other eye disease were excluded.

Institutional review board approved recruitment letters were mailed out to eligible participants. Letters were followed by a phone call from the study staff within 3 weeks to describe the study, confirm eligibility and interest, and schedule the telemedicine eye screening (visit 1) at one of seven PCPs or four Federally Qualified Health Center offices at the most convenient location for the participant. Eligible patients who were attending PCP appointments on the day the research team was conducting visit 1 eye screenings were referred directly by the PCP as "walk-ins" and were included in the study. Participation in the study, eye screening, and eye examination were offered at no cost to participants.

\section{TELEMEDICINE EYE SCREENING (VISIT 1)}

From April 1, 2015 to February 6, 2017, one trained ocular technician and two health educators obtained the participants' medical and ocular history, including history of diabetes and hypertension, and family history of glaucoma. Best-corrected visual acuity, measured with correction if the participant had glasses or contact lenses, was obtained using the digital acuity system ClearChart 2 (Reichert Technologies, Depew, NY). The ocular technician measured the intraocular pressure (IOP) using a rebound tonometer TA01i (iCare, Vantaa, Finland) and captured two monoscopic fundus photographs and one anterior segment photograph per eye using a nonmydriatic, auto-focus, handheld fundus camera (Volk Pictor, Mentor, $\mathrm{OH})$. The camera allowed for a 45-degree field to view the retina. One fundus photograph was centered on the macula and the other on the optic nerve.

All clinical and visual measurements, demographic data, and fundus/optic nerve images were uploaded within 24 hours to the Wills Eye Hospital Telemedicine Department's passwordencrypted, Health Insurance Portability and Accountability Act compliant server and were evaluated by a trained retina reader and a glaucoma specialist within 5 days. Fundus images were classified as abnormal, normal, or unreadable. Participants with unreadable images, abnormal findings, or ocular hypertension (OHTN) with an IOP 22-29 mmHg in at least one eye with a normal image were invited to return to the same location for a confirmatory eye examination (visit 2).

Abnormal findings consisted of suspicious nerves [based on vertical cup-to-disc (C:D) ratio] $>0.65$ in average and large discs or $<0.5$ in small discs, rim width $(<0.2$ in any area, including optic disc notches), vertical C:D ratio asymmetry of $>0.2$ between eyes, any disc hemorrhage, nerve fiber layer defect, or beta zone peripapillary atrophy in association with 


\section{HARK ET AL.}

suspicious rim-thinning and retinal pathology. Images were interpreted by the retinal reader and glaucoma specialist as unreadable if $<0.75$ of the macula was clearly visible (i.e., blurry vessels and insufficient focus precluding detection of microaneurysms) or if disc images with the entire optic nerve were not clearly visible. Participants with an unreadable image in one eye and a normal fundus image in the other eye or unreadable in both eyes were deemed unreadable. Those with an unreadable image in one eye and an abnormal image in the other eye were deemed abnormal. Participants with normal images and normal IOP were not invited for visit 2 and were recommended to return to an eye care provider within 1 year. These individuals were not included in the study analyses.

All participants were sent a letter with their results, and those invited for the eye examination (visit 2) were also called up to three times by the study staff to schedule visit 2 at the same primary care office. In addition, the participants' PCPs were notified of the upcoming eye examination appointment, and a follow-up letter was sent to the participants' home address with the date, time, and location of their visit 2 eye examination.

\section{CONFIRMATION EYE EXAMINATION (VISIT 2)}

From June 2, 2015 to June 30, 2017, confirmatory eye examinations began with an ocular technician evaluating the participant's ocular, medical, and family history, measuring best-corrected visual acuity using ClearChart 2 (Reichert Technologies), and performing visual field analysis using the Octopus 300 visual field analyzer (Haag Streit Diagnostics, Bern, Switzerland).

A glaucoma fellowship-trained ophthalmologist conducted the eye examination, which consisted of anterior segment slitlamp biomicroscopy (Zeiss, Dublin, CA), IOP measurements using a Goldmann applanation tonometer, gonioscopy with compression of the corneal dome if indicated, measurement of pupil size and central corneal thickness (iPac; Reichert, Inc., Depew, NY or Pachmate; DGH Technology, Exton, PA), and dilated or undilated funduscopic evaluation. All participants with diabetes were dilated, while others were dilated at the ophthalmologist's discretion. At the end of the confirmatory eye examination, the ophthalmologist reviewed the results and determined a final diagnosis using standard American Academy of Ophthalmology Practice Pattern Guidelines. ${ }^{23}$

Lens status was graded by the examining ophthalmologist as any type of cataract $(1+, 2+, 3+, 4+)$, pseudophakic, "clear lens," or other. The study design did not use the Lens Opacities Classification System in this community-based setting. Cataracts were categorized by the examining ophthalmologist as "non-visually significant" or "visually significant" depending on the severity of the participant's symptoms, such as glare and vision loss. Visually significant cataracts were defined by the ophthalmologist based on visual acuity 20/40 or worse in at least one eye, in addition to visual symptoms consistent with their cataract status.

\section{DATA MANAGEMENT AND STATISTICAL ANALYSIS}

Study data were collected and managed using Research Electronic Data Capture and the electronic medical records at Wills Eye Hospital. Demographics (age, sex, race, ethnicity), clinical characteristics (smoking, diabetes, family history of glaucoma, hypertension, visual acuity, glycated hemoglobin, last eye examination date), and insurance type were collected for all participants and summarized with mean and standard deviation or frequencies and percentages. Differences between participants with no cataract diagnosis (excluding pseudophakic) and those diagnosed with nonvisually significant and visually significant cataract ("cataract severity") were compared using analysis of variance, Fisher's exact test, or Pearson's Chi-squared test. Among participants who attended the visit 2 eye examination, the prevalence of any ocular diagnosis and cataract severity was summarized and compared to screening results using Fisher's exact tests. A cumulative logistic regression model was used to test for association between the ordinal end point of the visit 2 cataract severity (no cataract diagnosis, nonvisually significant, and visually significant cataract) and potential predictors, including age, gender, diabetes, visual acuity, and smoking status. Statistical analysis was performed using R 3.5 (R Foundation for Statistical Computing, Vienna, Austria). ${ }^{24}$

\section{Results}

A total of 906 participants completed the visit 1 telemedicine eye screening in the PCP setting, and 536 (59.2\%) participants were invited to return for visit 2 (Fig. 1). Of those invited, 347 (64.7\%) attended the visit 2 eye examination. In 18 participants, both eyes were pseudophakic or one eye was pseudophakic and the other eye was normal and they were excluded from further analysis, leaving 329 for analysis as shown in Table 1. Of those examined at visit 2, 267 (76.9\%) participants were diagnosed with cataracts, of which 38 (14.2\%) had visually significant cataract.

The mean age of participants without cataracts or who had not had cataract surgery $(n=62)$ was $52.4 \pm 9.7$ years; those with nonvisually significant cataracts was $60.5 \pm 9.5$ years, and those with visually significant cataracts was $66.9 \pm$ 9.4 years $(p<0.001)$. A total of 157 participants $(58.8 \%$; 157) 267) with any cataracts were female. African American participants represented the majority of those screened and 


\section{CATARACT CLASSIFICATIONS FOLLOWING EYE SCREENING}

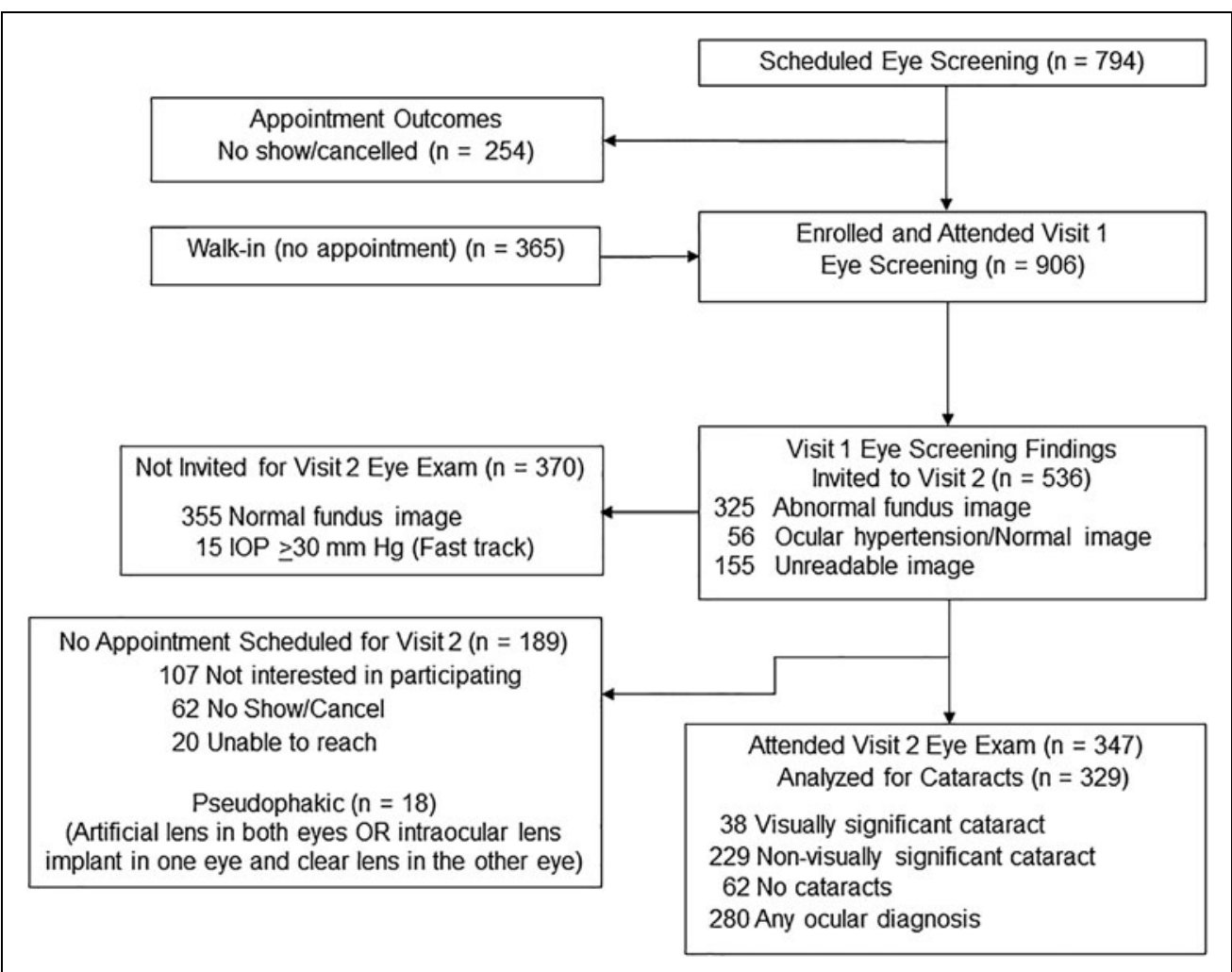

Fig. 1. Philadelphia Telemedicine Glaucoma Detection and Follow-Up Study: Consort Diagram of Eye Screening Findings and Eye Examination Cataract Results. (Top right) 794 scheduled an appointment for an eye screening at visit 1. (Top left) 254 cancelled or did not show up to their screening appointment. (Second from the top right) 906 individuals enrolled in our study and were screened. (Second from the top left) 365 participants attended without an appointment. (Second from the bottom left) 355 participants had normal fundus images, 15 participants were "Fast Tracked" due to an IOP >30 mmHg. (Second from bottom right) 536 participants were invited for a follow-up eye examination (visit 2). (Bottom left) 189 participants did not attend visit 2, including reasons for not attending, 18 participants who were pseudophakic were excluded from the analysis.(Bottom right) 347 participants returned for an eye examination, 280 were confirmed with at least one ocular diagnosis, 38 visually significant cataracts, and 229 nonvisually significant cataracts. IOP, intraocular pressure.

examined [62.5\% (167/267)].Differences in age, visual acuity (better eye and worse eye), and diabetes were observed between participants at the three levels of cataract severity (Table 1). Visual acuity [converted to logarithm of the minimum angle of resolution (logMAR)] in participants with visually significant cataracts was significantly worse in both eyes compared to those diagnosed with nonvisually significant cataracts and those with no cataract diagnosis $(p<0.001$ for better eye and $p=0.017$ for worse eye). Of those diagnosed with visually significant cataract, $76.3 \%$ had diabetes, while only 58.5\% of those with nonvisually significant cataract and $41.9 \%$ of those with no cataract diagnosis had diabetes ( $p=0.003$ ).

A cumulative logistic regression model with proportional odds assumption was performed with potential predictors of age, sex, diabetes, visual acuity, and smoking status. The final multivariable model showed that the severity of cataract increased with age, diabetes, and visual acuity in the worse eye. Specifically, for every 1-year increase in age, the odds of having more severe cataracts at the visit 2 eye examination increased by $8.5 \%$ [odds ratio $(\mathrm{OR})=1.09, p<0.001,95 \%$ confidence interval (CI: 1.06-1.12)]. Compared to participants without diabetes, those with diabetes had twice the odds of having more severe cataracts $(\mathrm{OR}=2.21, p=$ 0.002, 95\% CI: 1.34-3.71). For every $0.1 \log M A R$ increase in visual acuity in the worse eye, the odds of having more severe cataracts increased by $22.4 \%(\mathrm{OR}=1.22, p<$ 0.001, 95\% CI: 1.14-1.33).

Eye screening (visit 1) findings for those diagnosed with cataracts at the eye examination (visit 2) are shown in Table 2. Among the 38 participants diagnosed with visually significant cataracts at visit 2, 15 (39.5\%) were originally classified at the visit 1 eye screening as having an unreadable fundus image, 21 (55.3\%) had an abnormal fundus image, and 2 (5.3\%) had OHTN.

As shown in Table 3, the 267 (229 with nonvisually significant +38 with visually significant cataracts) participants with cataracts all had at least one other ocular diagnosis concurrently with cataracts, including 155 glaucoma suspects, 29 glaucoma, 17 OHTN, 23 anatomically narrow angle, 33 diabetic retinopathy, and 18 other retina conditions. Of the ocular conditions listed in Table 3, only narrow angle was associated with lens status.

Cataract lens grading is shown in Table 4. Of those who attended the Visit 2 eye examination, 76.9\% were diagnosed with some form of cataract ranging from mild (1+) to severe (4+). Of those with visually significant cataracts, moderate and severe lens grading was observed at $73.7 \%$ in the better eye and $97.4 \%$ in the worse eye. 


\section{Table 1. Baseline Demographic and Clinical Characteristics of Participants}

\begin{tabular}{|c|c|c|c|c|c|}
\hline VARIABLES, $n(\%)$ & $\begin{array}{l}\text { ALL PARTICIPANTS } \\
\text { (EXCLUDES } 18 \\
\text { PSEUDOPHAKIC) } \\
(N=329)\end{array}$ & $\begin{array}{l}\text { NO CATARACT } \\
\text { DIAGNOSIS } \\
\text { (EXCLUDES } 18 \\
\text { PSEUDOPHAKIC) } \\
(N=62)(18.8 \%)\end{array}$ & $\begin{array}{l}\text { DIAGNOSED WITH } \\
\text { NONVISUALLY } \\
\text { SIGNIFICANT } \\
\text { CATARACT } \\
(N=229)(69.6 \%)\end{array}$ & $\begin{array}{c}\text { DIAGNOSED WITH } \\
\text { VISUALLY } \\
\text { SIGNIFICANT } \\
\text { CATARACT } \\
(N=38)(11.6 \%)\end{array}$ & $p$ \\
\hline Age in years, mean $( \pm S D)$ & $59.7 \pm 10.3$ & $52.4(9.7)$ & $60.5(9.5)$ & $66.9(9.4)$ & $<0.001^{*}$ \\
\hline Sex, female, $n(\%)$ & $199(60.5 \%)$ & $42(67.7)$ & $134(58.5)$ & $23(60.5)$ & 0.442 \\
\hline African American & $215(66.8 \%)$ & $48(78.7)$ & $147(64.2)$ & $20(52.6)$ & \multirow[t]{4}{*}{0.122} \\
\hline Caucasian & 49 (15.2\%) & $3(4.9)$ & 37 (16.2) & $9(23.7)$ & \\
\hline Hispanic & $34(10.6 \%)$ & $5(8.2)$ & $24(10.5)$ & $5(13.2)$ & \\
\hline Asian & $16(5.0 \%)$ & $3(4.9)$ & $12(5.2)$ & $1(2.6)$ & \\
\hline $\mathrm{HbA}_{1 \mathrm{c}}$, mean $\pm \mathrm{SD}, \%$ & $8.2 \pm 2.3(n=176)$ & $8.4(2.2)(n=25)$ & $8.3(2.4)(n=123)$ & $7.8(1.8)(n=28)$ & 0.598 \\
\hline
\end{tabular}

Visual acuity (at Visit 1), mean $( \pm S D), \log M A R$

\begin{tabular}{|c|c|c|c|c|c|}
\hline Better eye & $0.1 \pm 0.2$ & $0.1 \pm 0.1$ & $0.1 \pm 0.2$ & $0.3 \pm 0.2$ & $<0.001^{*}$ \\
\hline Worse eye & $0.3 \pm 0.4$ & $0.2 \pm 0.2$ & $0.3 \pm 0.3$ & $0.8 \pm 0.7$ & $0.017^{*}$ \\
\hline Current smoker, $n(\%)$ & $92(28.0 \%)$ & $18(29.0)$ & $62(27.1)$ & $12(31.6)$ & 0.794 \\
\hline Hypertension, $n(\%)$ & $229(69.6 \%)$ & $33(53.2)$ & $169(73.8)$ & $27(71.1)$ & 0.696 \\
\hline Hypertension type, $n(\%)^{* *}$ & $(n=315)$ & $(n=60)$ & $(n=219)$ & $(n=36)$ & \\
\hline Normal $(<120 / 80 \mathrm{mmHg})$ & $52(16.5 \%)$ & $12(20.0)$ & $32(14.6)$ & $8(22.2)$ & \multirow[t]{4}{*}{0.225} \\
\hline Elevated $(120-129 /<80 \mathrm{mmHg})$ & $46(14.6 \%)$ & $6(10.0)$ & $38(17.4)$ & $2(5.6)$ & \\
\hline Stage $1(130-139 / 80-89 \mathrm{mmHg})$ & $112(35.6 \%)$ & $24(40.0)$ & 78 (35.6) & $10(27.8)$ & \\
\hline Stage 2 (>140/90 mmHg) & $105(33.3 \%)$ & $18(30.0)$ & $71(32.4)$ & $16(44.4)$ & \\
\hline \multicolumn{6}{|l|}{ Insurance type, $n(\%)$} \\
\hline Medicaid only & $127(38.6 \%)$ & $27(43.5 \%)$ & $87(38.0)$ & $13(34.2)$ & \multirow[t]{7}{*}{0.352} \\
\hline Medicare only & $75(22.8 \%)$ & $3(4.8 \%)$ & $57(24.9)$ & $15(39.5)$ & \\
\hline Medicare + Medicaid & $5(1.5 \%)$ & $2(3.2 \%)$ & $3(1.3)$ & $0(0.0)$ & \\
\hline Medicare + Private & $5(1.5 \%)$ & $0(0.0 \%)$ & $4(1.7)$ & $1(2.6)$ & \\
\hline Private only & $95(28.9 \%)$ & $25(40.3 \%)$ & $61(26.6)$ & $9(23.7)$ & \\
\hline No insurance & $21(6.4 \%)$ & $5(8.1 \%)$ & $16(7.0)$ & $0(0.0)$ & \\
\hline Unknown & $1(0.3 \%)$ & $0(0.0 \%)$ & $1(0.4)$ & $0(0.0)$ & \\
\hline \multicolumn{6}{|c|}{ Time since last visit with an ophthalmologist, $n(\%)$} \\
\hline Within past 2 years & $134(40.7 \%)$ & $26(41.9 \%)$ & $91(39.7)$ & $17(44.7)$ & \multirow[t]{3}{*}{0.217} \\
\hline More than 2 years ago & $162(49.2 \%)$ & $25(40.3 \%)$ & $119(52.0)$ & $18(47.4)$ & \\
\hline Never & $33(10.0 \%)$ & $11(17.7 \%)$ & $19(8.3)$ & $3(7.9)$ & \\
\hline
\end{tabular}

Bold values indicate statistical significance at the 0.05 level.

${ }^{*}$ Comparing no cataract, nonvisually significant, and visually significant cataract using analysis of variance or Chi-squared test.

${ }^{* *}$ Based on ranges determined by Whelton et al. ${ }^{36}$ 


\section{CATARACT CLASSIFICATIONS FOLLOWING EYE SCREENING}

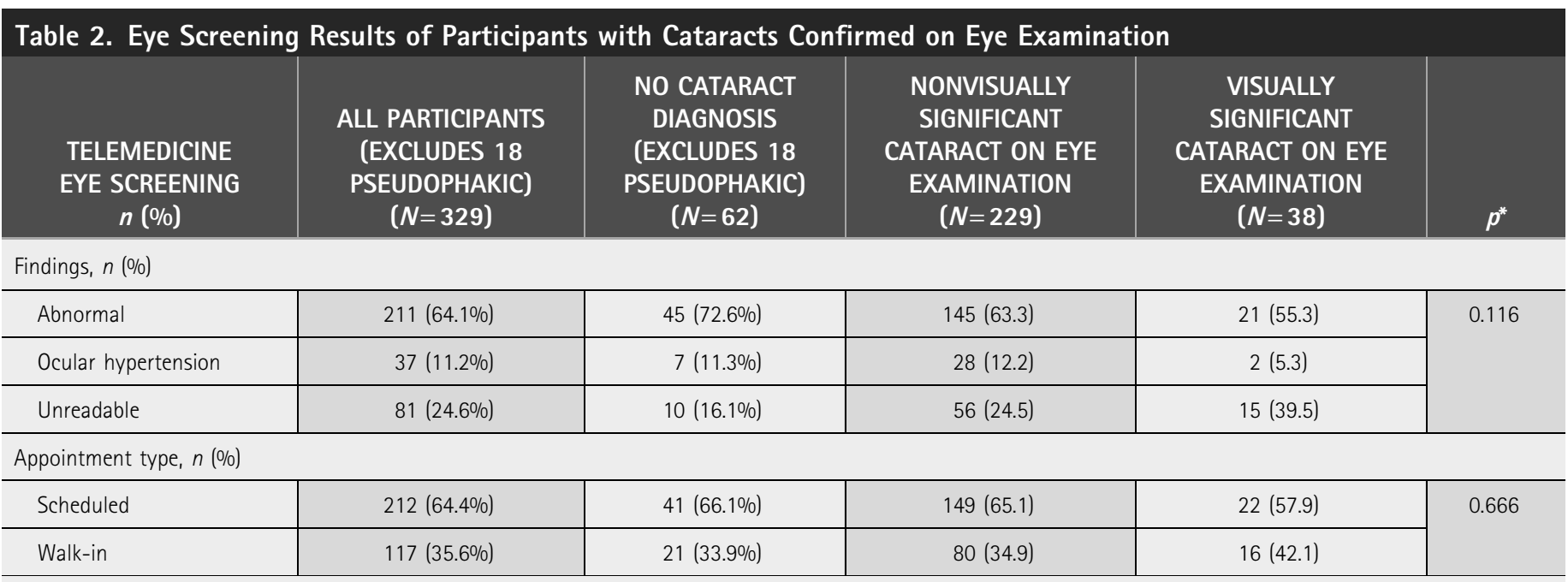

*Comparing cataract severity (no cataract, nonvisually significant, and visually significant cataract) by Chi-squared test.

\section{Discussion}

Cataracts are one of the most common causes of visual impairment in the United States, despite being a highly treatable condition. ${ }^{7}$ The Philadelphia Telemedicine Glaucoma Detection and Follow-Up Study was able to detect high rates of cataracts among an underserved group of participants who screened abnormal or had an unreadable fundus image and returned for a comprehensive eye examination by an ophthalmologist in the PCP setting. Our findings support other studies that highlight the importance of age and the presence of comorbidities, such as diabetes, in screening for cataracts in well-defined groups., ${ }^{5,6,25}$ Regarding diabetes, 76.3\% of participants diagnosed with visually significant cataracts had diabetes compared to $58.5 \%$ of those with nonvisually significant cataracts $(p=0.003)$.

Our study showed a high prevalence of cataracts in this predominately underserved African American population. ${ }^{22}$ Geographic and racial disparities still exist with regards to the detection and treatment of cataracts. ${ }^{9,10}$ Shahbazi et al. found that although African Americans have a lower gender-specific cataract prevalence, they are also less likely to undergo necessary cataract surgery. ${ }^{10}$ Furthermore, Wu et al. found that

\begin{tabular}{|c|c|c|c|c|c|}
\hline $\begin{array}{c}\text { EYE EXAMINATION } \\
\text { DIAGNOSES } \\
n(\%)\end{array}$ & $\begin{array}{l}\text { ALL PARTICIPANTS } \\
\text { (EXCLUDES } 18 \\
\text { PSEUDOPHAKIC) } \\
(N=329)\end{array}$ & $\begin{array}{l}\text { NO CATARACT } \\
\text { DIAGNOSIS } \\
\text { (EXCLUDES } 18 \\
\text { PSEUDOPHAKIC) } \\
(N=62)\end{array}$ & $\begin{array}{c}\text { NONVISUALLY } \\
\text { SIGNIFICANT } \\
\text { CATARACT ON EYE } \\
\text { EXAMINATION } \\
(N=229)\end{array}$ & $\begin{array}{c}\text { VISUALLY } \\
\text { SIGNIFICANT } \\
\text { CATARACT ON EYE } \\
\text { EXAMINATION } \\
(N=38)\end{array}$ & $p^{* *}$ \\
\hline Glaucoma & $34(10.3 \%)$ & $5(8.1 \%)$ & $24(10.5)$ & $5(13.2)$ & 0.717 \\
\hline Glaucoma suspects & $190(57.8 \%)$ & 35 (56.5\%) & $135(59.0)$ & $20(52.6)$ & 0.739 \\
\hline Ocular hypertension & $25(7.6 \%)$ & $8(12.9 \%)$ & $16(7.0)$ & $1(2.6)$ & 0.481 \\
\hline Anatomically narrow angle & $23(7.0 \%)$ & $0(0.0 \%)$ & $19(8.3)$ & $4(10.5)$ & $0.020^{*}$ \\
\hline Diabetic retinopathy & 39 (11.9\%) & $6(9.7 \%)$ & $26(11.4)$ & $7(18.4)$ & 0.380 \\
\hline Other retinal pathology* & $22(6.7 \%)$ & $4(6.5 \%)$ & $17(7.4)$ & $1(2.6)$ & 0.688 \\
\hline
\end{tabular}

Ocular hypertension defined as intraocular pressure $>21 \mathrm{~mm} \mathrm{Hg}$ with normal fundus image. Bold values indicate statistical significance at the 0.05 level.

*Includes age-related macular degeneration, macular pigmentary changes, and drusen.

**Comparing cataract severity (no cataract, nonvisually significant, and visually significant cataract) using Chi-squared test. 


\section{HARK ET AL.}

\begin{tabular}{|c|c|c|c|c|c|}
\hline \multicolumn{6}{|l|}{ Better eye, $n(\%)$} \\
\hline Pseudophakic & $13(4.0 \%)$ & & $6(2.6 \%)$ & 7 (18.4\%) & \multirow{4}{*}{$<0.001^{*}$} \\
\hline Mild (1+) & 168 (51.1\%) & & $165(72.1 \%)$ & 3 (7.9\%) & \\
\hline Moderate (2+) & 79 (24.0\%) & & $55(24.0 \%)$ & $24(63.2 \%)$ & \\
\hline Severe $(3+)$ & $6(1.8 \%)$ & & $2(0.9 \%)$ & $4(10.5 \%)$ & \\
\hline Clear lens & 62 (18.8\%) & $62(100 \%)$ & 0 & 0 & \multirow[t]{6}{*}{$<0.001^{*}$} \\
\hline Pseudophakic & 0 & & 0 & 0 & \\
\hline Mild (1+) & 166 (50.5\%) & & $165(72.1 \%)$ & $1(2.6 \%)$ & \\
\hline Moderate $(2+)$ & 84 (25.5\%) & & 61 (26.6\%) & 23 (60.5\%) & \\
\hline Severe $(3+)$ & $13(4.0 \%)$ & & $3(1.3 \%)$ & $10(26.3 \%)$ & \\
\hline Severe $(4+)$ & $4(1.2 \%)$ & & $0(0.0 \%)$ & $4(10.5 \%)$ & \\
\hline
\end{tabular}

${ }^{*}$ Comparing 229 nonvisually significant versus 38 visually significant cataract participants using chi-squared test. Bold values indicate statistical significance at the 0.05 level.

black race was associated with decreased odds of receiving cataract surgery within both Medicare and the Veterans Health Administration. ${ }^{26}$ Interestingly, African Americans also have a greater likelihood of having complex cataract surgery among fee-for-service Medicare beneficiaries compared to whites (OR $=1.90 ; 95 \% \mathrm{CI}: 1.75-2.08) .{ }^{27}$ Javitt et al., concluded that the likelihood of an individual undergoing cataract surgery increased with age (from 65 to 94 years). ${ }^{28}$ Other studies, such as the Barbados Eye Study, showed that black populations had a higher prevalence of cortical cataracts, which strongly correlated with diabetes, hypertension, and abdominal obesity. ${ }^{29}$

With regards to the eye screening images in our study, unreadable images may indicate the presence of visually significant cataracts. ${ }^{30,31}$ The return rate of participants invited for the visit 2 eye examination was $64.7 \%$, which although slightly higher than observed in our previous study, suggests that there are still barriers to care that remain unaddressed. ${ }^{32}$ Due to our targeted population being from underserved areas in Philadelphia, we expected to find high rates of uninsured participants which could pose a barrier for future cataract surgery. However, the majority of participants diagnosed with cataracts $(93.6 \%)$ were insured. Our eye screenings and eye examinations were provided free of charge to all participants, which eliminated the cost barrier of accessibility to eye care. Therefore, the remaining multidimensional barriers to cataract surgery may be related to adherence to follow-up eye care rather than lack of insurance. ${ }^{32}$

Early identification of older adults with cataracts who would benefit from cataract surgery has been shown by Mennemeyer and Owsley to reduce the rate of motor vehicle collision; however, individuals are often reluctant to complain about these symptoms and seek surgery. ${ }^{33,34}$ An extensive review by Lamoureux summarizing the impact of cataract surgery from the participant's perspective, with a focus on second-generation participant-reported outcome measures, used Rasch analysis to explore their data. ${ }^{35}$ Evidence suggests that cataract surgery also improves visual functioning in comorbid eye disease, especially in the early stages.

Our study has several limitations. Since we targeted highrisk individuals, there may be selection bias, as these individuals are at higher risk for cataracts. In addition, there was 


\section{CATARACT CLASSIFICATIONS FOLLOWING EYE SCREENING}

no charge for the eye screening or eye examination, despite most participants in our study having health insurance, which may not be generalizable for most individuals in underserved communities. As seen in other outreach studies in underserved communities, there was a high rate of no-shows and rescheduling of participant appointments; therefore, consistent follow-up care in underserved communities remains a challenge that must be addressed. In addition, the scope of this study did not investigate the many factors that may contribute to participants not having cataract surgery or reasons for not attending the follow-up visits.

\section{Conclusion}

In conclusion, telemedicine has been widely studied as a tool in detecting ocular diseases such as diabetic retinopathy. The use of telemedicine in screening for cataracts is not commonly performed due to technical difficulties and the high likelihood for false negative and false positive results. In our study, a large number of participants with abnormal findings and unreadable fundus images on the visit 1 eye screening were diagnosed with cataracts at the confirmation visit 2 eye examination. Telemedicine vision screening programs can bridge the gap in health care for underserved communities and are an important opportunity for general ophthalmologists and cataract surgeons to receive referrals. As technology improves, newer screening tools for cataracts will emerge and partnering with community-based telemedicine programs involved in vision screening could be useful to reduce disparities in cataract surgery in underserved populations.

\section{Authors' Contributions}

The following authors report no financial disclosures: L.A.H., J.A., M.U., A.M., T.Z., S.H., B.E.L., S.L., and J.B.S.

L.J.K., Grant/Research Support: Allergan (Madison, NJ), Diopsys (Montville, NJ), Heidelberg Engineering (Heidelberg, Germany), Zeiss (Oberkichen, Germany); Consultant/Advisory Board: Allergan (Madison, NJ), Alcon (Sinking Spring, PA), Glaukos (San Clemente, CA), Aerie Pharm. (Bedminster, NJ), Diopsys (Montville, NJ), Mati Therapeutics (Austin, TX), Aerpio Therapeutics (Blue Ash, OH); Speakers List: Allergan (Madison, NJ), Alcon (Sinking Spring, PA), Glaukos (San Clemente, CA), Bausch \& Lomb (Rochester, NY); Aerie Pharm. (Bedminster, NJ); Stock Shareholder: Glaukos (San Clemente, CA), Mati Therapeutics (Austin, TX), Aerie Pharm. (Bedminster, NJ); Chief Medical Officer: Glaukos (San Clemente, CA).

M.W., Grant/Research Support: Allergan (Madison, NJ), Diopsys (Montville, NJ), Heidelberg Engineering (Heidelberg,
Germany), Iridex Corporation (Mountain View, CA), Orcam (Tel Aviv, Israel); Consultant/Advisory Board: Novartis (Basel, Switzerland).

L.R.P., Grant/Research Support: NEI (Bethesda, MD), Advisory Board for Eyenovia (New York, NY), Consultant for Bausch+Lomb, Inc. (Bridgewater, NJ).

J.A.H., Grant/Research Support: ThromboGenics (Iselin, NJ), Consultant: Janssen (Raritan, NJ), Merck (Kenilworth, NJ), Novartis (East Hanover, NJ), KalVista (Cambridge, MA), Spark Therapeutics (Philadelphia, PA), Lowy Medical Research Institute (La Jolla, CA), Board Member: Celgene Corporation (Summit, NJ).

J.S.M., Grant/Research Support: Allergan (Madison, NJ), Aerie Pharm. (Bedminster, NJ), Diopsys (Montville, NJ), Haag-Streit (Bern, Switzerland), Heidelberg Engineering (Heidelberg, Germany), Alcon/Novartis (Sinking Spring, PA), Glaukos (San Clemente, CA), Consultant/Advisory Board: Allergan (Madison, NJ), Alcon (Sinking Spring, PA), Aerie Pharm. (Bedminster, NJ), Glaukos, Inotek (Lexington, MA), MicroOptx (Minneapolis, MN), Speakers List: Aerie, Allergan (Madison, NJ), Alcon (Sinking Spring, PA).

\section{Acknowledgments}

The authors thanks the Centers for Disease Control and Prevention for funding the Philadelphia Telemedicine Glaucoma Detection and Follow-Up Study and for reviewing the article. The authors thank the Wills Eye Glaucoma Research Center research team and the Wills Eye Telemedicine Department. The authors thank their community partners: Temple Physicians, Inc., Public Health Management Corporation, Philadelphia Department of Public Health-Philadelphia District Five Health Center, Health Federation of Philadelphia, and Spectrum Health Center. The authors also thank our Scientific Advisory Board and Elizabeth Murdakhayev, BS, for assistance with the article submission.

\section{Disclosure Statement}

No competing financial interests exist.

\section{Funding Information}

This study was funded by the United States Centers for Disease Control and Prevention (CDC) Cooperative Agreement: U01 DP005127.

\section{REFERENCES}

1. Congdon N, O'Colmain $\mathrm{B}$, Klaver $\mathrm{CC}$, et al. Causes and prevalence of visual impairment among adults in the United States. Arch Ophthalmol 2004;122: 477-485.

2. National Eye Institute. Statistics and data: Cataracts. 2018. Available at https://nei.nih.gov/eyedata/cataract (Last accessed September 1, 2018). 


\section{HARK ET AL.}

3. World Health Organisation. Global data on visual impairment. 2018. Available at www.who.int/blindness/publications/globaldata/en (Last accessed September 1, 2018).

4. Pascolini D, Mariotti SP. Global estimates of visual impairment: 2010. Br J Ophthalmol 2012;96:614-618.

5. Asbell PA, Dualan I, Mindel J, Brocks D, Ahmad M, Epstein S. Age-related cataract. Lancet 2005;365:599-609.

6. Storey $P$, Munoz B, Friedman D, West $S$. Racial differences in lens opacity incidence and progression: the Salisbury Eye Evaluation (SEE) study. Invest Ophthalmol Vis Sci 2013;54:3010-3018.

7. Gray CS, Karimova G, Hildreth AJ, Crabtree L, Allen D, O'Connell JE. Recovery of visual and functional disability following cataract surgery in older people: Sunderland Cataract Study. J Cataract Refract Surg 2006;32:60-66.

8. Schein OD, Cassard SD, Tielsch JM, Gower EW. Cataract surgery among Medicare beneficiaries. Ophthalmic Epidemiol 2012;19:257-264.

9. Mundy KM, Nichols E, Lindsey J. Socioeconomic disparities in cataract prevalence, characteristics, and management. Semin Ophthalmo/ 2016;31: 358-363.

10. Shahbazi S, Studnicki J, Warner-Hillard CW. A cross-sectional retrospective analysis of the racial and geographic variations in cataract surgery. PLoS One 2015;10:e0142459.

11. Broman AT, Hafiz G, Muñoz B, et al. Cataract and barriers to cataract surgery in a US Hispanic population: Proyecto VER. Arch Ophthalmol 2005;123: 1231-1236.

12. Hark L, Waisbourd M, Myers JS, et al. Improving access to eye care among persons at high-risk of glaucoma in Philadelphia-design and methodology: The Philadelphia Glaucoma Detection and Treatment Project. Ophthalmic Epidemiol 2016;23:122-130.

13. Lewallen $S$, Courtright $P$. Recognising and reducing barriers to cataract surgery. Comm Eye Health 2000;13:20-21.

14. Lewallen $\mathrm{S}$, Roberts $H_{\text {, Hall }} A$, et al. Increasing cataract surgery to meet Vision 2020 targets; experience from two rural programmes in east Africa. Br J Ophthalmol 2005;89:1237-1240.

15. Chen $T$, Jin $L$, Zhou $Z$, et al. Factors influencing the output of rural cataract surgical facilities in China: The SHARP study. Invest Ophthalmol Vis Sci 2015; 56:1283-1291.

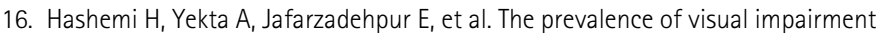
and blindness in underserved rural areas: A crucial issue for future. Eye (Lond.) 2017;31:1221-1228.

17. Labiris G, Panagiotopoulou EK, Kozobolis VP. A systematic review of teleophthalmological studies in Europe. Int J Ophthalmol 2018;11:314-325.

18. Ng M, Nathoo N, Rudnisky CJ, Tennant MT. Improving access to eye care: Teleophthalmology in Alberta, Canada. J Diabetes Sci Technol 2009;3:289296.

19. Bajwa A, Aman R, Reddy AK. A comprehensive review of diagnostic imaging technologies to evaluate the retina and the optic disk. Int Ophthalmol 2015; 35:733-755.

20. Mohammadpour M, Heidari Z, Mirghorbani M, Hashemi H. Smartphones, teleophthalmology, and VISION 2020. Int J Ophthalmol 2017;10:1909-1918.

21. Sanguansak $T$, Morley $K$, Morley $M$, et al. Comparing smartphone camera adapters in imaging post-operative cataract patients. J Telemed Telecare 2017;23:36-43.

22. Hark LA, Katz $\sqcup$, Myers JS, et al. Philadelphia Telemedicine Glaucoma Detection and Follow-Up Study: Methods and screening results. Am J Ophthalmol 2017; 181:114-124.

23. American Academy of Ophthalmology. Preferred Practice Pattern ${ }^{\circledR}$ guidelines. Comprehensive adult medical eye evaluation. American Academy of
Ophthalmology, 2015. Available at https://www.aao.org/clinical-statement/ frequency-of-ocular-examinations (Last accessed September 1, 2018).

24. R: A language and environment for statistical computing. $R$ Foundation for Statistical Computing, Vienna, Austria, 2018. Available at https://www .R-project.org (Last accessed September 1, 2018).

25. Richter GM, Chung J, Azen SP, Varma R. Prevalence of visually significant cataract and factors associated with unmet need for cataract surgery: Los Angeles Latino Eye Study. Ophthalmology 2009;116:2327-2335.

26. Wu AM, Wu CM, Tseng VL, et al. Characteristics associated with receiving cataract surgery in the US Medicare and Veterans Health Administration populations. JAMA Ophthalmol 2018;136:738-745.

27. Mahr MA, Hodge DO, Erie JC. Racial/ethnic differences in rates of complex cataract surgery among United States Medicare beneficiaries. J Cataract Refract Surg 2018;44:140-143.

28. Javitt JC, Kendix M, Tielsch JM, et al. Geographic variation in utilization of cataract surgery. Med Care 1995;33:90-105.

29. Leske MC, Wu SY, Hennis A, Connell AM, Hyman L, Schachat A. Diabetes, hypertension, and central obesity as cataract risk factors in a black population. The Barbados Eye Study. Ophthalmology 1999;106:35-41.

30. Hark LA, Myers JS, Rahmatnejad K, et al. Philadelphia Telemedicine Glaucoma Detection and Follow-Up Study: Analysis of unreadable fundus images. J Glaucoma 2018;27:999-1008.

31. Hark LA, Myers JS, Ines A, et al. Philadelphia Telemedicine Glaucoma Detection and Follow-Up Study: Confirmation between eye screening and comprehensive eye examination diagnoses. Br J Ophthalmol 2019;0:1-7.

32. Hark LA, Leiby BE, Waisbourd M, et al. Adherence to follow-up recommendations among individuals in the Philadelphia Glaucoma Detection and Treatment Project. J Glaucoma 2017;26:697-701.

33. Mennemeyer ST, Owsley C, McGwin G, Jr. Reducing older driver motor vehicle collisions via earlier cataract surgery. Accid Anal Prev 2013;61:203-211.

34. Owsley C, McGwin G, Jr., Sloane M, et al. Impact of cataract surgery on motor vehicle crash involvement by older adults. JAMA 2002;288:841-849.

35. Lamoureux EL, Fenwick E, Pesudovs K, Tan D. The impact of cataract surgery on quality of life. Curr Opin Ophthalmol 2011;22:19-27.

36. Whelton PK, Carey RM, Aronow WS, et al. 2017 ACC/AHA/AAPA/ABC/ACPM/ AGS/APhA/ASH/ASPC/NMA/PCNA guideline for the prevention, detection, evaluation, and management of high blood pressure in adults: a report of the American college of cardiology/American heart association task force on clinical practice guidelines. Hypertension 2017;71:e13-e115.

Address correspondence to: Lisa A. Hark, PhD, RD

Columbia University Vagelos College of Physicians and Surgeons

Edward S. Harkness Eye Institute 635 West 165th Street, Suite 504 New York, NY 10032 USA

E-mail: lah112@cumc.columbia.edu

Received: July 1, 2019

Revised: August 28, 2019

Accepted: September 3, 2019

Online Publication Date: November 13, 2019 